\title{
Reduction in Birth Weight Associated With Smoking Among Young and Older-Age Women
}

\author{
A. ROBERTO FRISANCHO AND SHELLEY L. SMITH \\ Center for Human Growth and Development (A.R.F.) and Department of \\ Anthropology (S.L.S.), University of Michigan, Ann Arbor, Michigan \\ 48109
}

\begin{abstract}
This study examined the combined effects of maternal smoking and maternal age on birth weight. A sample of 1,851 white, full-term infants (37 to 42 weeks) born to primiparous mothers ranging in age from 18 to 41 years was derived from the database of the Child Health and Development Studies (CHDS), available through the National Technical Information Service (NTIS) of the U.S. Department of Commerce. The mothers were classified into three age groups-young, middle-aged, and older-aged-corresponding respectively to values below the 15th, between the 15th and 85th, and at or above the 85th percentile of age.

Analyses of the data show that the reduction in birth weight associated with maternal smoking when compared with nonsmoking averaged $181 \mathrm{gm}$ for the young group (18 to 20 years), $162 \mathrm{gm}$ for the middle-aged group (21 to 29 years), and $154 \mathrm{gm}$ for the older-aged group ( 30 to 41 years). These differences are independent of total income. Hence it appears that the birth weight-reducing effect of smoking is not enhanced among women of older reproductive ages (30 to 41 years). Furthermore, the reduction in birth weight is dose responsive. That is, the greater the number of cigarettes smoked per day, the lower is the resulting mean birth weight and the higher is the proportion of low-birth-weight infants.
\end{abstract}

Simpson (1957) was the first to report a reduction in birth weight among the offspring of mothers who smoked during pregnancy. Subsequently several studies confirmed this finding (e.g., Butler et al., 1972; Naeye, 1981; Garn, 1985). These studies have shown that maternal smoking is associated with a reduction in birth weight varying between 100 and $250 \mathrm{gm}$. Since approximately $30 \%$ of women of reproductive age in the United States smoke (U.S. Department of Health and Human Services, 1984) and since many women currently are choosing to postpone the age of first pregnancy, there is the possibility that the reduction in birth weight associated with smoking could be increased among women of older reproductive ages. Thus the present study addressed the combined effects of maternal smoking and maternal age on birth weight.

\section{MATERIALS AND METHODS Sample}

A sample of 1,851 white, full-term infants ( 37 to 42 weeks) born to primiparous moth- ers ranging in age from 18 to 41 years was derived from the database of the Child Health and Development Studies (CHDS), available through the National Technical Information Service (NTIS) of the U.S. Department of Commerce. The data were obtained from studies conducted at the Kaiser Permanente Medical Center from June 1959 to September 1966. The present analyses include only those samples coded as white. Premature delivery (less than 37 weeks) was cause for exclusion.

\section{Measurements and analyses}

The measurements included evaluation of the following variables: 1) maternal age; 2) gestational age of newborns in weeks (derived from information on the last menstrual period); 3) birth weight (for live-born infants only); 4) gravida prepregnancy weight; 5) weight of gravida at interview or registra-

Received January 13, 1989; accepted August 28, 1989. 
tion (hereafter referred to as "pregnancy weight"); 6) maternal smoking habits, including number of cigarettes smoked per day; and 7) total income scale $(1,<\$ 2,500$; $2, \$ 2,500-4,999 ; 3, \$ 5,000-5,999 ; 4, \$ 6,000-$ 6,$999 ; 5, \quad \$ 7,000-7,999 ; 6, \$ 8,000-8,999$; $7, \$ 9,000-9,999 ; 8, \$ 10,000-12,499 ; 9$, $\$ 12,500-14,999 ; 10, \geqslant \$ 15,000$ ).

The mothers were considered "smokers" if they reported smoking during pregnancy and as "nonsmokers" if they denied smoking both before and during pregnancy. There were 1,043 nonsmokers and 808 smokers. Comparisons of mean birth weight were adjusted for differences in total income scale by analysis of covariance.

\section{RESULTS AND DISCUSSION General characteristics}

The general characteristics of the two groups are given in Table 1 . It is evident that there were no significant differences in maternal age, prepregnancy weight, gestational age, and total income scale associated with maternal smoking. However, smokers' infants weighed significantly $(P<0.0001)$ less than did nonsmokers' infants, with the average difference being 164 gm (Fig. 1). Pregnancy weight was slightly, but significantly, lower for nonsmokers.

\section{Age trends}

As shown in Figure 2, the reduction rate of birth weight associated with age is similar in both smokers and nonsmokers. Furthermore, for purposes of this analysis, the mothers were classified based on percentile ranges of age into three categories: 1) young, age range (18 to 20 years) below the 15 th percentile for age; 2 ) middle-aged, age range (21 to 29 years) between the 15th and 85th percentile for age; and 3) older-aged, age range (30 to 41 years) at or above the 85 th percentile for age. Table 2 compares the mean birth weight of infants born to these three groups of women. From these data it is evident that the reduction in birth weight associated with maternal smoking when compared with nonsmoking averaged 181 gm for the young group (18 to 20 years), 162 gm for the middle-aged group (21 to 29 years), and $154 \mathrm{gm}$ for the older-aged group (30 to 41 years).

\section{Dosage}

As shown in Table 3 and Figure 3, there is also a clear dose-response effect of smoking on mean birth weight and the percentage of infants with low birth weight (birth weight $<2,500 \mathrm{gm})$. That is, the greater the number of cigarettes smoked per day, the lower is the resulting mean birth weight and the higher is the proportion of low-birth-weight infants.

The present data suggest that the greater risk of having infants who have experienced impaired fetal growth associated with increased age at first birth is not differentially aggravated by smoking beyond the effect noticed at younger reproductive ages. This finding is contrary to that reported by Cnattingius et al. (1985). Based on a prospective clinical study of infants born to Swedish women, those investigators reported that the reduction in birth weight associated with age was more pronounced among smokers. It should be further noted that in the Swedish study the group of "nonsmokers" included light smokers ( 0 to 9 cigarettes per day) and nonsmokers, while the group of "smokers" smoked greater than or equal to 20 cigarettes per day. Yet, as Table 3 in the present study shows, women who smoke up to 9 cigarettes per day do exhibit a reduction in mean birth weight and a slightly increased percentage of low-birth-weight infants when compared with nonsmokers. The sources of the age-related birth weight differential as-

TABLE 1. Comparison of maternal characteristics of nonsmoking and smoking white primiparous mothers (Mean $\pm S D)$

\begin{tabular}{lrrrc}
\hline Variables & $\mathrm{N}$ & Nonsmokers & $\mathrm{N}$ & \multicolumn{1}{c}{ Smokers } \\
\hline Age (years) & 1,043 & $24.5 \pm 4.5$ & 808 & $24.2 \pm$ \\
Prepregnancy weight (kg) & 892 & $57.3 \pm 7.8$ & 675 & 4.5 \\
Pregnancy weight (kg) & 1,028 & $59.2 \pm 8.2$ & 800 & $87.1 \pm$ \\
Gestational age (weeks) & 1,043 & $40.3 \pm 1.3$ & 808 & $9.5 \pm$ \\
Birth weight (gm) & 1,043 & $3,385.2 \pm 438.9$ & 808 & $3,220.9 \pm 4.3$ \\
Total income scale & 1,043 & $4.3 \pm 2.5$ & 808 & 1.3 \\
\hline
\end{tabular}

${ }^{* *} P<0.0001$

${ }^{*} P<0.05$. 


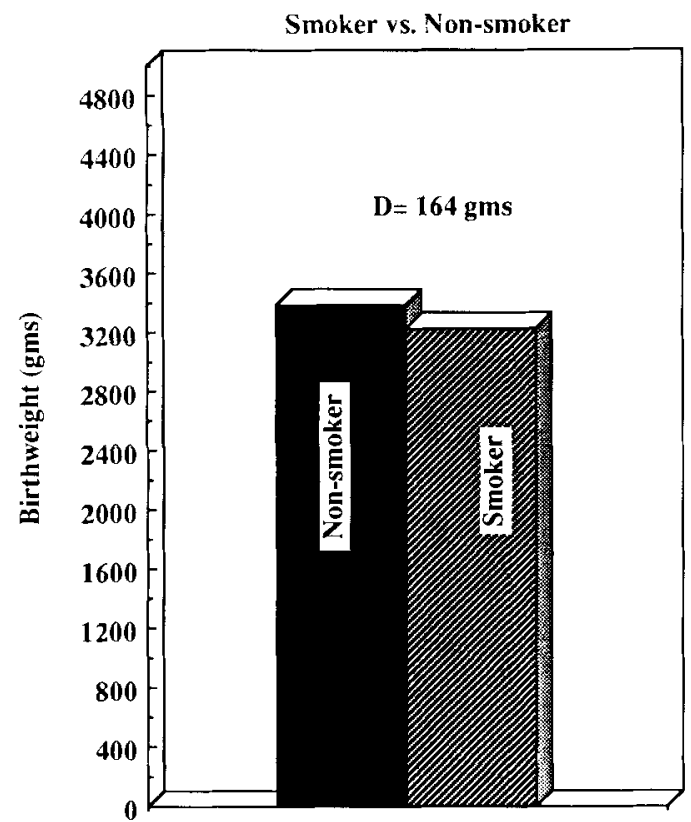

TABLE 2. Comparison of mean birth weights of infants of nonsmoking and smoking white primiparous mothers by age group ${ }^{1}$

\begin{tabular}{|c|c|c|c|}
\hline $\begin{array}{l}\text { Age group } \\
\text { (years) }\end{array}$ & $\begin{array}{c}\text { Smoking } \\
\text { habit }\end{array}$ & $\mathrm{N}$ & Mean $\pm \mathrm{SE}$ \\
\hline $\begin{array}{l}18-20 \\
18-20 \\
\text { Difference }\end{array}$ & $\begin{array}{c}\text { Nonsmoker } \\
\text { Smoker } \\
181 \mathrm{gm}, P\end{array}$ & $\begin{array}{l}199 \\
167 \\
001\end{array}$ & $\begin{array}{l}3,414.6 \pm 31.6 \\
3,234.0 \pm 34.7\end{array}$ \\
\hline $\begin{array}{l}21-29 \\
21-29 \\
\text { Difference }\end{array}$ & $\begin{array}{c}\text { Nonsmoker } \\
\text { Smoker } \\
162 \mathrm{gm}, P\end{array}$ & $\begin{array}{c}709 \\
548 \\
1001\end{array}$ & $\begin{array}{l}3,380.8 \pm 16.4 \\
3,218.6 \pm 18.7\end{array}$ \\
\hline $\begin{array}{l}30-41 \\
30-41 \\
\text { Difference }\end{array}$ & $\begin{array}{c}\text { Nonsmoker } \\
\text { Smoker } \\
154 \mathrm{gm}, P\end{array}$ & $\begin{array}{r}135 \\
93 \\
01 \\
\end{array}$ & $\begin{array}{l}3,365.1 \pm 38.0 \\
3,211.1 \pm 45.6\end{array}$ \\
\hline
\end{tabular}

${ }^{1}$ Adjusted for differences in total income scale by analysis of covariance.

Fig. 1. Comparison of birth weights of infants born to smokers and nonsmokers. D, difference.

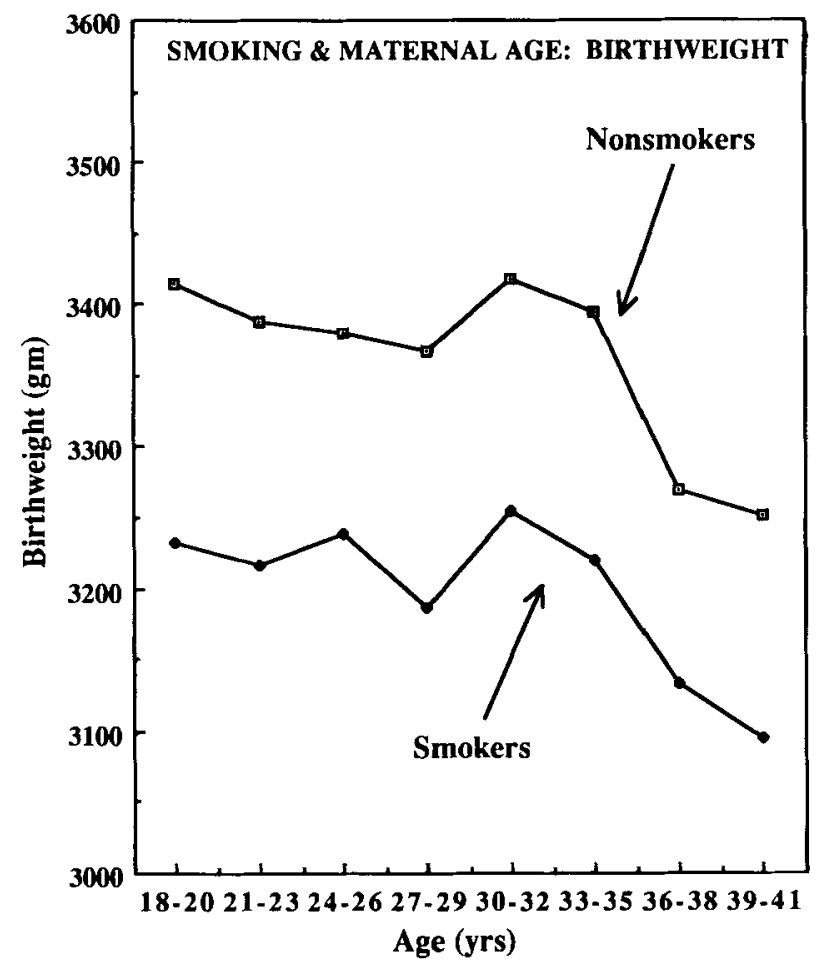

Fig. 2. Birth weights of infants of smokers and nonsmokers by maternal age. 
TABLE 3. Relationship between maternal cigarette consumption and birth weight of infants born to primiparous white mothers

\begin{tabular}{lrcc}
\hline $\begin{array}{l}\text { Cigarettes } \\
\text { per day }\end{array}$ & $\mathrm{N}$ & Mean $\pm \mathrm{SE}^{1}$ & \% LBW \\
\hline None & 1,043 & $3,385.2 \pm 13.5$ & 2.78 \\
$1-9$ & 237 & $3,268.8 \pm 28.4$ & 2.95 \\
$10-19$ & 211 & $3,202.7 \pm 30.0$ & 4.74 \\
$20 \geq$ & 353 & $3,199.6 \pm 23.2$ & 5.95 \\
F-test & & $22.8, P<0.0001$ & \\
\hline
\end{tabular}

${ }^{1}$ Means adjusted for total income scale by analysis of covariance. ${ }^{2}$ Birth weight $<2,500 \mathrm{gm}$.

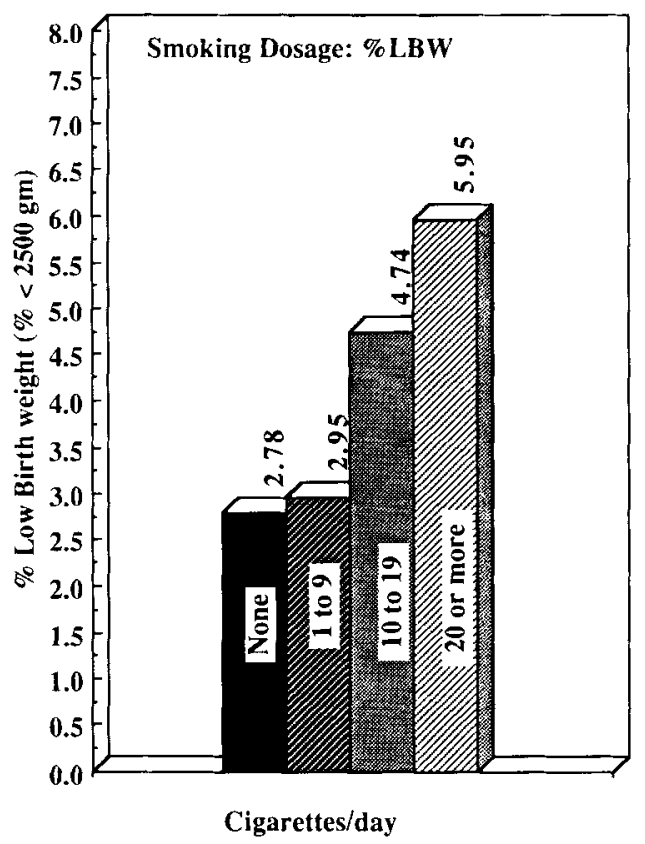

Fig. 3. Dosage effect of smoking on birth weight. sociated with smoking as opposed to nonsmoking in the Swedish study and the lack of such a difference in the present study remain unexplained.

In conclusion, the present study indicates that smoking is associated with a reduction in birth weight of $164 \mathrm{gm}$. However, the reduction in birth weight associated with smoking is not enhanced with older age.

\section{ACKNOWLEDGMENTS}

This research is supported in part by grant MCR-73-29 of The Division of Maternal and Child Health, Bureau of Health Care, Delivery, and Assistance, Rockville, MD. We thank Audrey Tran for her assistance in manuscript preparation.

\section{LITERATURE CITED}

Butler NR, Goldstein H, Ross EM (1972) Cigarette smoking in pregnancy: Its influence on birth weight and perinatal mortality. Br. Med. J. 2:127-130.

Cnattingius S, Axelsson O, Eklund G, Lindamark G (1985) Smoking, maternal age and fetal growth. Obstet. Gynecol. 66:449-452.

Garn SM (1985) Smoking and human biology. Hum. Biol. 57:505-523.

Naeye RL (1981) Influence of maternal cigarette smoking during pregnancy on fetal and childhood growth. Obstet. Gynecol. 57:18-21.

Simpson WJ (1957) A preliminary report on cigarette smoking and the incidence of prematurity. Am. J. Obstet. Gynecol. 73:808-815.

United States Department of Health and Human Services (1984) The Health Consequences of Smoking: A Report of the Surgeon General. Washington, D.C.: US Government Printing Office. 